\title{
Developing the Oxidation Kinetic Model for Magnetite Pellet
}

\author{
T.K. SANDEEP KUMAR, N.N. VISWANATHAN, H. AHMED, A. DAHLIN, \\ C. ANDERSSON, and B. BJORKMAN
}

Oxidation is a vital phenomenon for magnetite pellets in their excursion through the furnace during induration. One of the pre-requisites for magnetite pellets to achieve homogeneously structured good quality pellets is to have complete oxidation before sintering begins. Partially oxidized magnetite pellets, upon sintering, might result in inhomogeneous structured pellets which could be detrimental to pellet quality. It is necessary to understand the mechanisms responsible for magnetite oxidation, and hence, it is intended in this study to investigate experimentally as well as develop a mathematical model based on oxidation kinetics. Oxidation of pellets is largely influenced by the oxidation kinetics of particles and hence should be studied at particle as well as at pellet scale. The principles of the Grain Model have been adopted to develop the Oxidation Model at pellet scale, whereas the particles' oxidation follows the Avrami Kinetic Model. Isothermal oxidation experiments performed Thermogravimetric Analyzer showed that oxidation rate of magnetite at pellet scale contained two peaks. They were complemented well by oxidation rates predicted from the model. Further, the pellet was investigated microstructurally at pellet and particle scale to substantiate the findings from the experiments and the model. The oxidation model developed is used to predict the progression of oxidation in the magnetite pellet with respect to the reaction time at three different temperatures $\left(873 \mathrm{~K}, 973 \mathrm{~K}\right.$, and $1073 \mathrm{~K}\left(600{ }^{\circ} \mathrm{C}, 700{ }^{\circ} \mathrm{C}\right.$, and $\left.\left.800{ }^{\circ} \mathrm{C}\right)\right)$ and at four levels of oxygen $(0.21$, $0.30,0.60$, and $1.00 \mathrm{~atm})$ in the oxidizing gas.

https://doi.org/10.1007/s11663-018-1423-4

(C) The Author(s) 2018

\section{INTRODUCTION}

Pelletization is one of the important processes of the iron and steelmaking operations for sustainable and effective use of raw materials. It utilizes the crushed, beneficiated, and ground iron ore fines from the mines, and agglomerates them into spherical pellets. These pellets are heat hardened or indurated to impart sufficient strength. Iron ore pellets provide several benefits over other ferrous burdens in terms of strength and reducibility, while magnetite pellets in particular offer advantages in terms of energy due to the exothermic nature of its oxidation to hematite during

T.K. SANDEEP KUMAR, C. ANDERSSON, and B. BJORKMAN are with the Lulea University of Technology (LTU), 97187 Lulea, Sweden. Contact e-mail: kamesh.sandeep@ltu.se N.N. VISWANATHAN is with the Indian Institute of Technology Bombay (IITB), Mumbai 400076, India. H. AHMED is with the Lulea University of Technology (LTU) and also with the Center of Metallurgical Research and Development Institute, Cairo 12422, Egypt. A. DAHLIN is with the LuossavaaraKiirunavara Aktiebolag (LKAB), 98381 Malmberget, Sweden.

Manuscript submitted May 10, 2018.

Article published online October 30, 2018. induration. ${ }^{[1]}$ The moist magnetite concentrate is mixed with additives such as flux and binder (bentonite) to produce green pellets. Thereafter, the green pellets undergo physico-chemical changes during induration primarily by oxidation at low temperatures $(573 \mathrm{~K}$ to $1073 \mathrm{~K}\left(300{ }^{\circ} \mathrm{C}\right.$ to $\left.800{ }^{\circ} \mathrm{C}\right)$ ) and sintering at higher temperatures $\left(>1273 \mathrm{~K}\left(1000^{\circ} \mathrm{C}\right)\right) .^{[1,2]}$

Ideally, it is desirable to have complete oxidation before the start of sintering to achieve best pellet properties. ${ }^{[2,3]}$ When a partially oxidized pellet consisting of a hematite shell and magnetite core begins to sinter, complete oxidation may not occur. This heterogeneity in the pellet structure can develop stresses owing to the difference in their sinter-ability which results in inferior pellet quality. ${ }^{[2-4]}$ Keeping the pellet at low temperature for a long residence time allows the oxidation to be completed before sintering, however, this limits the production rate. This necessitates understanding the induration process in a quantitative manner in order to design the optimum thermal and gas composition profile which will achieve the desired pellet quality without compromising the production rate. It is therefore intended to quantify both the oxidation as well as sintering phenomenon, to determine the kinetics 
through careful experimentation, and subsequently develop the model to capture the overall induration process.

In this quest, the current authors have carried out a detailed investigation of sintering kinetics and appropriate models have been developed to simulate the sintering of magnetite and oxidized magnetite. ${ }^{[5,6]}$ The experimental findings of sintered pellets at macroscopic level have further been substantiated by the degree of sintering evaluated microscopically. ${ }^{[7]}$ Subsequent to the sintering studies, the objective is now to investigate the oxidation phenomenon independently for the magnetite pellet and develop the model. Prior studies were done to understand the oxidation phenomenon of magnetite pellet, and various conceptual models were formulated. ${ }^{[8-15]}$ These postulated models are synonymous to the non-catalytic heterogeneous gas-solid reaction models for porous solids, namely, shrinking core model, pore diffusion, and the grain model. Researchers have adopted one of these models and investigated the reaction kinetics of porous solids experimentally, mostly limited to the pellet scale. ${ }^{[4,13,16-21]}$ Further, reactor scale models have been built upon considering these for reactions happening during the induration process. ${ }^{[22-26]}$

Oxidation proceeds from the periphery of the pellet farther into the pellet through diffusion of oxygen. As the pellet at the scale of 10 to $12 \mathrm{~mm}$ consists of particles at the scale of 10 to $100 \mu \mathrm{m}$, locally at any location in the pellet, the oxidation occurs at the scale of a particle. Therefore, the oxidation model needs to be developed both at particle and pellet scale. ${ }^{[10,11,15]}$ Among the various non-catalytic gas-solid reaction models, the Particle-Pellet or Grain Model is considered to describe the oxidation phenomenon of magnetite pellets in the most appropriate manner. ${ }^{[3,9,11,12,27]}$ Lately, Cho et $a l^{[28,29]}$ studied the kinetics of magnetite pellet oxidation experimentally at particle scale by assuming shrinking core mechanism as well as at the pellet scale and further demonstrated the oxidation model for pellet using the grain model concept.

Earlier researchers have proposed that the reaction kinetics of individual particles proceeds topo-chemically with the formation of a sharp reaction interface. $^{[2,12,13,16,28-30]}$ As the reaction front proceeds inwards in an individual particle, the reacting gas gets consumed with the formation of the product layer within the pellet and resists further transport of the reacting gas. They opine that at the particle scale, the oxidation is determined by the intrinsic reaction kinetics as well as diffusion of species through the product phase. The mechanism of this diffusion can be because of gaseous diffusion through the product layer if there are any pores in the product layer, or it can be through solid-state bulk diffusion, grain boundary diffusion, or diffusion through other imperfections in the product matrix. ${ }^{[14,31-35]}$ However, the activation energy obtained from the analysis using the sharp interface model does not clearly point to any of these mechanisms in isolation. ${ }^{[15,34,36]}$ In a previous study, authors have also investigated the oxidation kinetics of magnetite concentrate at the particle scale experimentally and proposed a suitable model describing the phenomenon. ${ }^{[3]}$ From the study, it can be inferred that the oxidation at the scale of particle or powder proceeds by nucleation and growth following Avrami mechanism, and growth of hematite into the magnetite matrix is by solid-state diffusion. These findings were substantiated by the microstructural examination of partially oxidized particles. It was found that hematite crystals were growing ahead of the reaction interface further into magnetite particles from the periphery towards the center.

Therefore, in the current work, it is intended to perform the experimental investigation on the oxidation of magnetite at the pellet scale, and subsequently develop the Pellet Oxidation Model, which predicts the oxidation behavior-progression under the given thermal and gaseous conditions. This has been carried out by adopting the principles of the grain model for gas-solid reactions at the pellet scale, integrated with the oxidation kinetics at the particle scale described by the Avrami Kinetic Model (AKM). It superimposes the diffusion of oxidizing gas radially through the pores of pellet along with the local heat transfer owing to the exothermic magnetite oxidation. The oxidation experiments were performed in a Thermogravimetric Analyzer (TGA) for magnetite pellet exposed to three levels of constant temperatures $(873 \mathrm{~K}, 973 \mathrm{~K}$, and $1073 \mathrm{~K}$ $\left(600{ }^{\circ} \mathrm{C}, 700{ }^{\circ} \mathrm{C}, 800{ }^{\circ} \mathrm{C}\right)$ ) and four levels of partial pressure of oxygen $(0.15,0.21,0.30$, and $1.00 \mathrm{~atm})$ in the oxidizing gas. The experimental profiles for oxidation fraction and oxidation rate have been compared with those predicted by the model.

\section{METHODS AND MATERIALS}

\section{A. Raw Materials}

The raw material used to prepare the pellets is a concentrate from the LKAB's mine in Malmberget, Sweden. The concentrate contains $\mathrm{Fe}_{3} \mathrm{O}_{4}>95$ pct with $\mathrm{Al}_{2} \mathrm{O}_{3}+\mathrm{SiO}_{2}<0.6$ pct. The concentrate was mixed with 7 pct moisture by weight and 0.5 pct dosage of bentonite as a binder in a laboratory mixer (Eirich R02). The green mix was then fed to a drum pelletizer (for micro balling) of $0.8 \mathrm{~m}$ diameter to produce nucleation seeds of 3.55 to $5.00 \mathrm{~mm}$ diameter and then further balled into green pellets. The green pellets with the desired size fraction of 9 to $10 \mathrm{~mm}$ were collected by screening. The green pellets were dried in an oven at $423 \mathrm{~K}\left(150^{\circ} \mathrm{C}\right)$ overnight.

\section{B. Oxidation Experiments}

Oxidation of individual magnetite pellets is studied with the help of a Thermogravimetric Analyzer (TGA) (Setaram 92). The TGA consists of a platinum wire basket where the magnetite green pellet is placed and suspended from the balance at the top, as shown in Figure 1.

The basket containing the pellet is then lowered into the graphite tube furnace (inner diameter $=15 \mathrm{~mm}$ and height $=300 \mathrm{~mm}$ ) with the help of an elevator. The maximum pellet size that can be used in this TGA is 


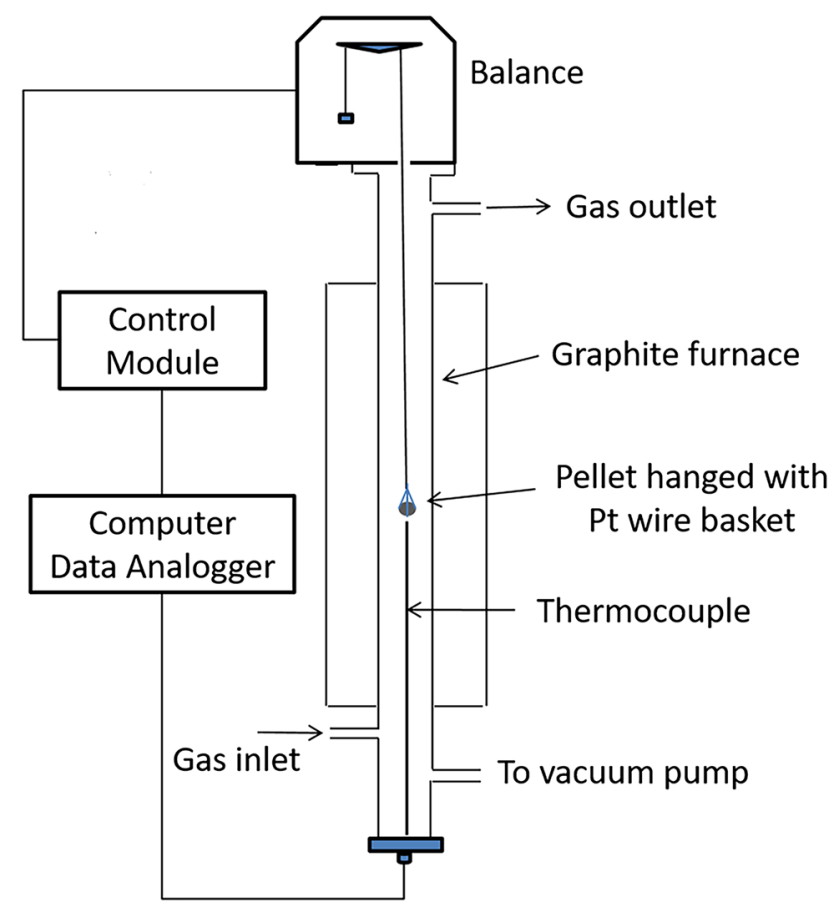

Fig. 1-Schematic of Setaram TG92-16 Thermogravimetric Analyzer (TGA).

Table I. Experiments for the Oxidation of Magnetite Pellets in TGA

\begin{tabular}{lrcc}
\hline Experiment & Temp, K $\left({ }^{\circ} \mathrm{C}\right)$ & $p_{\mathrm{O}_{2}}(\mathrm{~atm})$ & Hold Time (Min) \\
\hline P1 & $873(600)$ & 0.21 & 60 \\
P2 & $973(700)$ & 0.21 & 60 \\
P3 & $1073(800)$ & 0.21 & 60 \\
P4 & $873(600)$ & 0.15 & 60 \\
P5 & $873(600)$ & 0.30 & 60 \\
P6 & $873(600)$ & 1.00 & 60 \\
\hline
\end{tabular}

$10 \mathrm{~mm}$ in diameter, and hence the size of the pellets used in the study has been limited to 9 to $10 \mathrm{~mm}$. The S-type thermocouple placed beneath the sample is used to measure the gas temperature adjacent to the pellet surface. The mixture of 21 pct $\mathrm{O}_{2}+79$ pct $\mathrm{N}_{2}$ has been used as an oxidizing gas with the help of a gas mixer at a flow rate of $300 \mathrm{~mL} / \mathrm{min}$. The gas flow rate has been optimized by starvation tests for pellet oxidation. The furnace was heated up to the desired temperature at a rate of $20 \mathrm{~K} / \mathrm{min}\left(20^{\circ} \mathrm{C} / \mathrm{min}\right)$, held at that temperature for 60 minutes, and cooled at a rate of $20 \mathrm{~K} / \mathrm{min}\left(20^{\circ} \mathrm{C} /\right.$ $\mathrm{min}$ ) under the oxidizing atmosphere. Oxidation experiments are conducted at three temperature levels and partial pressure of oxygen at four levels, as shown in Table I. Each of the experiments are corrected for buoyancy effect by the background test in TGA using a standard alumina ball of $10 \mathrm{~mm}$ in diameter exposed to the respective thermal profile. The in-situ weight gain of the pellet is continuously captured at each second by the data logger.

\section{Interrupted Oxidation Tests}

The magnetite green pellets in the steel-wire basket were placed inside the vertical tube furnace at the desired oxidation temperature (say, $973 \mathrm{~K}\left(700^{\circ} \mathrm{C}\right)$ ) and partial pressure of oxygen (say, $0.21 \mathrm{~atm}$ ) at the flow rate of $300 \mathrm{~mL} \mathrm{~min}{ }^{-1}$. The partially oxidized magnetite pellets were taken out from the furnace after oxidizing for 120 , 240 , and 480 seconds. The partially oxidized magnetite pellets were quenched instantaneously by transferring into the nitrogen bath. Thereafter, the oxidized pellets are cut in half, cold mounted in epoxy, and polished to $1 \mu \mathrm{m}$ in diamond paste for microstructural examination.

\section{MODEL DEVELOPMENT}

The concept of the grain model for gas-solid reaction system is utilized to develop the model for oxidation kinetics for a magnetite pellet. According to the grain model, the solid is a porous mass consisting of several particles or grains. At the pellet scale, the reacting gas diffuses through the macro-pores (between the particles or grains) from the surface towards the center. As the reacting gas diffuses into the pellet, the particles undergo a physico-chemical reaction by consuming the reacting gas. The rate of reaction at the particle scale depends on the kinetic parameters at the particle scale as well as the local concentration of reacting gas inside the pellet. ${ }^{[9,15,38]}$

While developing the model, it is assumed that the pellet with the average porosity of $\epsilon$ is made up of several mono-sized spherical magnetite particles of size, $\mathrm{d}_{p}$. The magnetite pellet also contains the particles of bentonite (binder) but they are assumed to be inert. When the pellet is exposed to the oxidation temperature, the magnetite particles oxidize to hematite according to Eq. [1], ${ }^{[1,2,29]}$ which is exothermic in nature.

$$
\mathrm{Fe}_{3} \mathrm{O}_{4}+\frac{1}{4} \mathrm{O}_{2}=\frac{3}{2} \mathrm{Fe}_{2} \mathrm{O}_{3}+\Delta \mathrm{H} ; \Delta \mathrm{H}=115 \mathrm{~kJ} \mathrm{~mol}^{-1} \text {. }
$$

As the temperature at the pellet surface increases, the particles at the surface start to oxidize and the diffusion of oxygen through the pores in the pellet determines the further oxidation of particles in the pellet interior. Therefore, the overall oxidation model is developed by adopting the pore diffusion kinetics of oxidizing gas, particle oxidation kinetics, and the associated heat transfer kinetics, in that order.

\section{A. Pore Diffusion Kinetics}

The oxidation of particles in the pellet is dependent on the diffusion rates of oxidizing gas through the pores in the pellet, and subsequently the mole fraction of oxygen $\left(X_{\mathrm{O}_{2}}\right)$ across the radial position in the pellet. As the oxygen diffuses in the pellet from the surface toward the center, it is consumed by the particles for oxidation, and hence, the mole fraction of oxygen decreases continuously. The resulting oxygen mole fraction from the magnetite particles is the input to the subsequent magnetite particles further into the pellet. The extent 
to which the oxygen diffuses in the pellet at the particular temperature and reaction time defines the inward progression of the oxidation front at the pellet scale.

The diffusion flux of $\mathrm{O}_{2}\left(\dot{N}_{\mathrm{O}_{2}}\right)$ from the oxidizing gas (composed of $\mathrm{O}_{2}$ and $\mathrm{N}_{2}$ ) inside the pellet ${ }^{[39]}$.

$$
\dot{N}_{\mathrm{O}_{2}}=-C D_{\mathrm{eff}} \frac{\mathrm{d}}{\mathrm{d} r} X_{\mathrm{O}_{2}}+X_{\mathrm{O}_{2}}\left(\dot{N}_{\mathrm{O}_{2}}+\dot{N}_{\mathrm{N}_{2}}\right),
$$

where $D_{\text {eff }}$ is effective diffusivity of oxidizing gas, $C$ is the molar concentration of oxidizing gas, $X_{\mathrm{O}_{2}}$ is the mole fraction of $\mathrm{O}_{2}$, and $\dot{N}_{\mathrm{O}_{2}}$ and $\dot{N}_{\mathrm{N}_{2}}$ are the diffusive flux of $\mathrm{O}_{2}$ and $\mathrm{N}_{2}$ in the oxidizing gas, respectively. Since $\dot{N}_{\mathrm{N}_{2}}=0$, Eq. [2] is simplified to Eq. [3].

$$
\dot{N}_{\mathrm{O}_{2}}=\frac{-D_{\text {eff }} C}{\left(1-X_{\mathrm{O}_{2}}\right)} \frac{\mathrm{d} X_{\mathrm{O}_{2}}}{\mathrm{~d} r} \text {. }
$$

The effective diffusivity of the oxidizing gas in the pellet is a function of porosity $(\epsilon)$ and tortuosity $(\tau)$ of the pellet, as mentioned in Eq. [4],

$$
D_{\text {eff }}=D_{\mathrm{O}_{2}-\mathrm{N}_{2}}\left(\begin{array}{l}
\epsilon \\
\tau
\end{array}\right)
$$

where $D_{\mathrm{O}_{2}-\mathrm{N}_{2}}$ is the diffusion coefficient of the oxidizing gas.

The consumption of oxygen during its progression through the pellet pores can be determined by the conservation of flux for the $\mathrm{O}_{2}$, according to Eq. [5],

$$
\frac{1}{r^{2}} \frac{\mathrm{d}}{\mathrm{d} r}\left(r^{2} \dot{N}_{\mathrm{O}_{2}}\right)-G(\dot{r})=0 .
$$

The corresponding boundary conditions for $\mathrm{O}_{2}$ diffusion are, at $r=R, \dot{N}_{\mathrm{O}_{2}}=k_{\mathrm{O}_{2}} C\left(X_{\mathrm{O}_{2, \text { surface }}}-X_{\mathrm{O}_{2, \text { bulk }}}\right)$ and, at $r=0, \frac{d X_{O 2}}{d r}=0$

$$
\begin{gathered}
\dot{G}(r)=\left(\dot{N}_{p}\right) \delta_{\mathrm{M}_{,} \mathrm{Fe}_{3} \mathrm{O}_{4}}(0.25) \frac{\mathrm{d} f}{\mathrm{~d} t}, \\
\dot{N}_{p}=\frac{(1-\epsilon)}{\frac{1}{6}\left(\pi \mathrm{d}_{p}^{3}\right)},
\end{gathered}
$$

where $\dot{G}(r)$ is the number of moles of $\mathrm{O}_{2}$ consumed at any radial location $r$ per unit volume of pellet per unit time and $\dot{N}_{p}$ is number of particles per unit volume of the pellet.

\section{B. Oxidation Kinetics of Particles}

The oxidation kinetics of magnetite particles follows the Avrami mechanism, represented by Eq. [8], as determined in the previous study. ${ }^{[37,40]}$ The rate of oxidation of particles locally at any location across the pellet depends on the mole fraction of the oxygen gas that has diffused to the particle surface, according to Eq. [9].

$$
\begin{gathered}
f=\left(1-e^{-a t^{n}}\right), \\
\frac{\mathrm{d} f}{\mathrm{~d} t}=n a \cdot e^{-a t^{n}} t^{n-1},
\end{gathered}
$$

where $f$ is the fraction of oxidation achieved isothermally after time $t$, while Avrami coefficients $a$ and $n$ are the rate constant and the time exponent which provides an insight into the mechanism and rate of growth. Oxidation is a thermally activated phenomenon, and hence, the degree and rate of oxidation of particles are expected to be affected by the local temperature in the pellet, according to the Arrhenius relation. ${ }^{[36,38,39]}$ The coefficients of Avrami equation are related to Arrhenius rate constant $(K)$ according to Eq. [10]. The activation energy $(Q)$ and pre-exponential factor $\left(K_{0}\right)$ for the range of variables studied were determined using the Arrhenius Equation as mentioned in Eq. [11].

$$
K=a^{\frac{1}{n}}
$$

$$
\ln \left(T K^{(1 / n)}\right)=\ln K_{0}-\frac{Q}{R T} .
$$

The activation energy was found to be $225 \mathrm{~kJ} \mathrm{~mol}^{-1}$ in the range of temperatures considered. ${ }^{[37]}$ Based on experimental data, an empirical relationship was obtained for the variation of $n$ and $K_{0}$ with respect to temperature, the partial pressure of oxygen, and mean particle size. These equations are as follows:

$$
\begin{aligned}
n= & 1.76 \times 10^{-4} T+0.1255 \ln \left(p_{\mathrm{O}_{2}}\right)-2.03 \\
& \times 10^{-4} T \cdot \ln \left(p_{\mathrm{O}_{2}}\right) .
\end{aligned}
$$

$$
\log _{10} K_{0}=11.46+0.786 p_{\mathrm{O}_{2}}-5.55 \times 10^{-4} \mathrm{~d}_{p} .
$$

The principle of superposition was used to determine the rate of oxidation under isothermal conditions as discussed in the previous study. ${ }^{[37]}$

\section{Heat Transfer}

The heat transfer within the pellet is modeled using the one-dimensional conduction equation (Eq. [14]) given below,

$$
\frac{\rho C_{p} \mathrm{~d} T}{\mathrm{~d} t}=\frac{1}{r^{2}} \frac{\mathrm{d}}{\mathrm{d} r}\left(r^{2} k_{\mathrm{eff}} \frac{\mathrm{d} T}{\mathrm{~d} r}\right)+H_{\mathrm{Gen}} .
$$

Here $k_{\text {eff }}$ is the effective conductivity of the pellet and $\dot{H}_{\text {gen }}$ is the exothermic heat generation due to local rate of oxidation.

Initially, the whole pellet is at ambient temperature, $t=0,0<r<R, T=T_{\text {ambient }}$. 
As the pellet is lowered into the furnace, the furnace temperature is assumed to be changing linearly. In the isothermal zone of the furnace, the furnace temperature is constant. The heat transfer to the pellet is primarily governed by radiative heat transfer. This is incorporated through the boundary condition, which can be written as Eq. [15],

$$
\left.-k_{\mathrm{eff}} \frac{\partial T}{\partial r}\right]_{r=R}=\sigma \varepsilon\left(T_{r=R}^{4}-T_{\text {furnace }}^{4}\right) .
$$

The effective thermal conductivity $\left(k_{\text {eff }}\right)$ used here is determined from the experiments on thermal diffusivity $(\alpha)$ measurements for the magnetite green pellets using the Laser Flash technique. ${ }^{[36,39,41]}$

\section{RESULTS AND DISCUSSIONS}

\section{A. Input Parameters}

Using the input parameters mentioned in Table II, the model predicts the overall oxidation fraction and rate of oxidation of the magnetite pellet. The model results also provide the distribution of temperature and mole fraction of $\mathrm{O}_{2}$ within the pellet, which helps in estimating the radial extent of diffusion of oxidizing gas into the pellet. The model also facilitates prediction of the progression of the oxidation front within the magnetite pellet with respect to time for the pellets exposed to different isothermal temperatures and partial pressures of oxygen in the oxidizing gas.

\section{B. Oxidation Fraction and Oxidation Rate for the Pellet}

The overall oxidation fractions and oxidation rates for the magnetite pellets with respect to time are predicted from the pellet oxidation kinetic model, and are shown in Figure 2. The profiles have been predicted for the magnetite pellets exposed to different temperatures and partial pressures of oxygen in oxidizing gas. The predicted profiles are compared with those obtained from the oxidation experiments for pellets conducted in the TGA. The weight gain during the oxidation of magnetite pellets is converted to their corresponding fraction of oxidation $\left(f_{\mathrm{TGA}}\right)$ by equating with respect to the theoretical weight gain according to Eq. [16]. The theoretical or maximum weight gain $\left(\Delta W_{\max }\right)$ evaluated for the pellets during oxidation of magnetite to hematite used in this study is 3.24 pct.

$$
f_{\mathrm{TGA}}=\frac{\left(\frac{W_{f}-W_{i}}{W_{i}}\right) \times 100}{\Delta W_{\max }}=\frac{\Delta W_{\mathrm{TGA}}}{\Delta W_{\max }},
$$

where $\Delta W_{\mathrm{TGA}}$ is the percentage weight change measured during oxidation in TGA between the initial weight $\left(W_{i}\right)$ and final weight $\left(W_{f}\right)$ of the pellet.

The oxidation fraction of a pellet increases at a rapid rate initially, and thereafter increases gradually at a slow rate once it reaches the plateau region as shown in Figure 2(a). This is similar to the behavior of magnetite particles as reported earlier. ${ }^{[37]}$ This implies that the oxidation of magnetite on pellet scale is also a two-step phenomenon, as reported previously by several researchers. ${ }^{[2,16,28,30,42]}$ The degree of oxidation (fraction) is found to be increasing with temperature from $873 \mathrm{~K}$ to $1073 \mathrm{~K}\left(600{ }^{\circ} \mathrm{C}\right.$ to $\left.800{ }^{\circ} \mathrm{C}\right)$, whereas the degree of oxidation tends to attain a similar extent with increasing partial pressure of oxygen in the oxidizing gas at the same temperature. The predicted oxidation fraction profiles are in fair agreement at $873 \mathrm{~K}\left(600{ }^{\circ} \mathrm{C}\right)$ in comparison to those determined experimentally, whereas it is over-predicting at higher temperatures at $p_{\mathrm{O}_{2}}$ of $0.21 \mathrm{~atm}$. However, the predicted oxidation fraction profiles for pellets exposed to different $p_{\mathrm{O}_{2}}$ at $873 \mathrm{~K}$ $\left(600{ }^{\circ} \mathrm{C}\right)$ are also in fine agreement as compared to the experimental ones, but with the exception at $p_{\mathrm{O}_{2}}$ of $1.00 \mathrm{~atm}$, where it is slightly over-predicted.

Table II. Input Parameters to the Pellet Oxidation Kinetic Model

\begin{tabular}{lc}
\hline Particle variables & $35 \times 10^{-6} \mathrm{~m}$ \\
Particle size & $3.455 \mathrm{pct}^{-1}$ \\
Maximum weight gain for $\mathrm{Fe}_{3} \mathrm{O}_{4}$ particles during oxidation & $460 \mathrm{~kJ} \mathrm{~mol}^{-1}$ \\
Magnetite oxidation heat & $225 \mathrm{~kJ} \mathrm{~mol}^{-1}$ \\
Activation energy & $10 \times 10^{-3} \mathrm{~m}$ \\
Pellet variables & $30 \mathrm{pct}$ \\
Size of the pellet & $0.15 \mathrm{~atm}$ \\
Porosity of pellet & $0.21 \mathrm{~atm}$ \\
Partial pressure of $\mathrm{O}_{2}$ in the oxidizing gas & $0.30 \mathrm{~atm}$ \\
& $1.00 \mathrm{~atm}$ \\
& $300 \mathrm{~K}$ \\
Initial temperature of the pellet & $873 \mathrm{~K}\left(600{ }^{\circ} \mathrm{C}\right)$ \\
Surrounding or Furnace temperature & $973 \mathrm{~K}\left(700{ }^{\circ} \mathrm{C}\right)$ \\
& $1073 \mathrm{~K}\left(800{ }^{\circ} \mathrm{C}\right)$ \\
Thermal conductivity for magnetite pellet & $1.5 \mathrm{~W} \mathrm{~m}{ }^{-1} \mathrm{~K}^{-1}$ \\
Emissivity of magnetite pellet (reasonable to assume near black body) & 0.8 \\
Mass Transfer coefficient across the pellet & $1.02 \times 10^{-2} \mathrm{~m} / \mathrm{s}$ \\
Number of cells in the pellet & 100 \\
Time interval in each cell & $0.01 \mathrm{~s}$ \\
Holding time at isothermal temperature & $3600 \mathrm{~s}$ \\
\hline
\end{tabular}



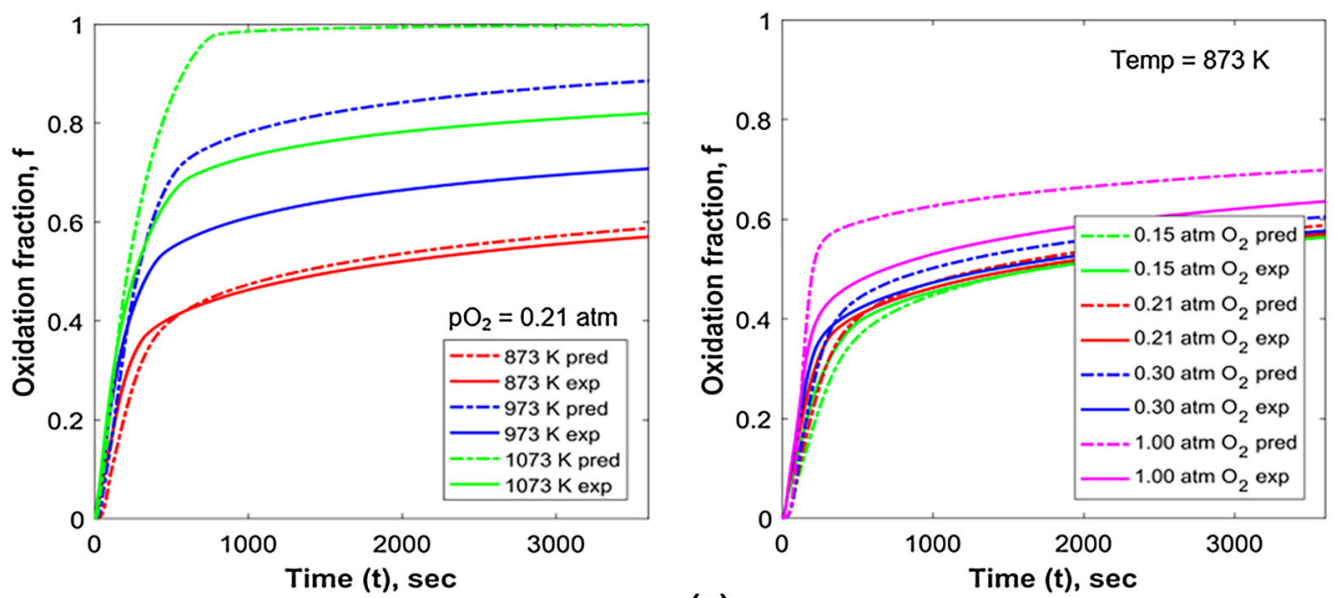

(a)
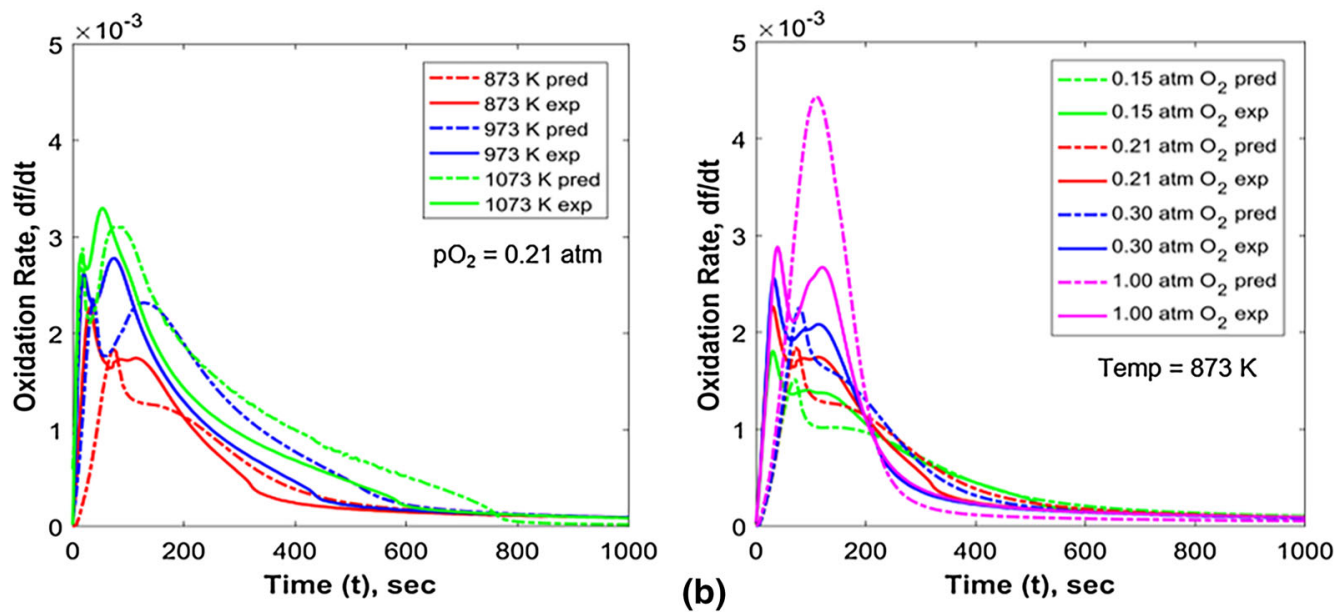

Fig. 2-Overall oxidation fraction and oxidation rate profiles predicted by Pellet Oxidation Kinetic Model for (a) different isothermal temperatures and $(b)$ different partial pressure of oxygen in oxidizing gas for magnetite pellets and compared with those obtained experimentally from TGA.

The rate of oxidation determined from the TGA experiments and the model, plotted as function of time at different temperatures as well as at different partial pressures of oxygen is shown in Figure 2(b). The rate of oxidation with time obtained from the TGA experimental data shows interesting behavior; two peaks at high temperatures and at lower temperatures the second peak evolves to a plateau. This type of behavior either has not been reported or discussed for magnetite pellet oxidation in previous studies. ${ }^{[28,42]}$ The model is able to capture this behavior. Although a similar behavior with oxygen partial pressures is also observed in the experimental rates of oxidation, the model has captured this behavior only to a limited extent. It should be noted that it is difficult to avoid initial transients in TGA experiments. Earlier researchers, ${ }^{[28,42]}$ in their TGA experiments, had allowed the magnetite pellet sample to come to a uniform furnace temperature under inert atmosphere and subsequently the inert gas was switched to an oxidizing atmosphere. However, depending on the volume of the TGA reactor and flow rate of the gas, it would take some time to reach a uniform gas composition in the reactor. In the present experiments, as mentioned earlier, the sample was lowered from room temperature to the reactor zone where temperature and gas composition were already at the desired level. Here, the initial thermal transients in the pellet cannot be eliminated. Therefore, the peaks could be arising from these initial thermal transients.

In order to analyze the possible reasons for this behavior, simulation experiments were conducted. When simulations are carried out with pellets at the furnace temperature $\left(873 \mathrm{~K}\left(600{ }^{\circ} \mathrm{C}\right)\right.$, from the start of oxidation (please note that experimentally this was not possible, as the pellet is lowered to the high-temperature zone), the rate of oxidation shows a monotonic decrease in rate of oxidation with increasing time, as depicted in Figure 3. The thermal conductivity of the pellet did not show significant variation in the rate of oxidation curves. Simulation experiments carried out without considering the heat of oxidation showed a significant decrease in peak intensity, though the shapes of the curves remained similar. However, simulation experiments with changing diffusivity of oxygen, mass transfer coefficient, and pre-exponential factor for the particle kinetics changed the oxidation curves significantly. It 


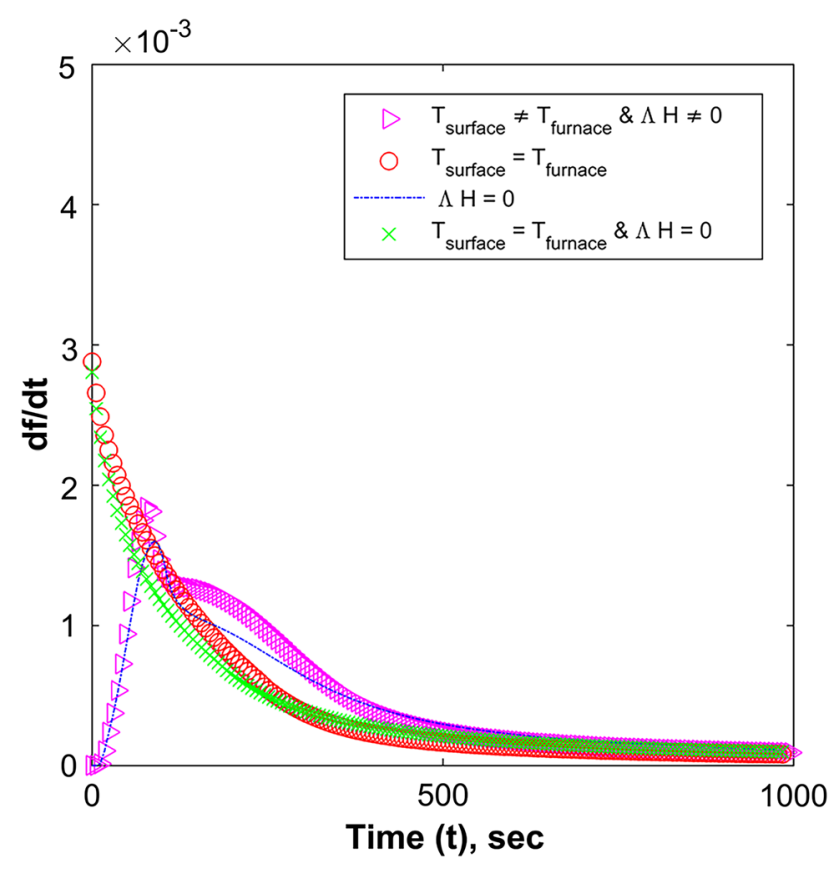

Fig. 3-Predicted oxidation rate profiles investigating different cases with respect to $T_{\text {surface }}, T_{\text {furnace }}$ and $\Delta H$.

may be noted that particle oxidation kinetics showed a large initial rate followed by a sharp decrease in rate at higher extents of oxidation. Similarly, local temperature variation due to oxidation heat can also change the rates of oxidation significantly. These effects in conjunction with diffusion of oxygen result in such non-monotonic behavior. It should be also noted that the effect of oxygen partial pressures on the particle oxidation kinetics has been experimentally obtained only for a single temperature. Possibly, more experiments on particle oxidation varying the oxygen partial pressure and temperatures can give better predictions at the pellet scale.

However, it is observed from Figure 2 that there is a deviation between the predicted and experimental oxidation rate curves. It is to be noted that the magnetite pellet chosen in this study for the TGA experiments consists of multi-sized particles in the desired proportion. Hence, the finer-sized particles within the pellet oxidize at a rapid rate with respect to the coarser particles. It is therefore postulated that the presence of fine particles in the pellet increases the oxidation rate in the experiments as compared to that predicted with mono-sized particles.

In order to affirm this understanding, microstructural investigation has been performed at both pellet scale and particle scale. For this purpose, the interrupted oxidation tests for magnetite pellets have been designed in such a way that it can help in following the progress of oxidation front at pellet as well as particle scale.

The optical microstructures of partially oxidized magnetite for 120 and 480 seconds were captured at the pellet scale, as shown in Figure 4. The optical microstructures at particle scale across the radial distance from the surface to the oxidation front and to the center of the pellet are also depicted in Figure 4. It can be seen that the pellet oxidation front observed has progressed farther into the pellet, whereas the particle oxidation front has not yet reached to the center of the particles. This infers that the oxidation front at pellet scale and the particle scale travels at different rates. It seems that the diffusion of oxygen gas is limited beyond the pellet oxidation front, and hence, the particles did not start to oxidize. However, fine particles at the surface of the pellet are either completely oxidized or have reacted to a significant extent as compared to the relatively coarser particles. This substantiates the findings postulated from the oxidation rate curves from TGA experiments as well as predicted from the pellet oxidation kinetic model.

\section{Oxidation Front Progression Within the Pellets}

The oxidation kinetic model developed in this study is further used to predict the progress of the oxidation of magnetite at the pellet scale across the radial distance with respect to temperature and oxygen content.

\section{Elevation of oxidation temperature}

The oxidation fraction across the radial positions in the pellet at different reaction times is predicted at three temperatures $\left(873 \mathrm{~K}, 973 \mathrm{~K}\right.$, and $1073 \mathrm{~K}\left(600{ }^{\circ} \mathrm{C}\right.$, $700{ }^{\circ} \mathrm{C}$, and $800{ }^{\circ} \mathrm{C}$ )) using the model, as shown in Figure 5. The results from the model show that the oxidation front is getting sharper with the increase in temperatures from $873 \mathrm{~K}$ to $1073 \mathrm{~K}\left(600{ }^{\circ} \mathrm{C}\right.$ to $\left.800{ }^{\circ} \mathrm{C}\right)$ after the same oxidation time for given partial pressure $(0.21 \mathrm{~atm})$ of oxygen in the oxidizing gas. Although, when the pellet is oxidized to longer time, the model shows that pellet oxidizes homogeneously and attains higher fraction of oxidation with increasing temperature.

The representation of the progress of magnetite oxidation on the radial plots is shown in Figure 6 for the above-mentioned three temperatures after 120, 240, and 480 seconds at $p_{\mathrm{O}_{2}}=0.21 \mathrm{~atm}$. A video clip is also attached to this paper depicting the progress of oxidation for these temperatures for better realization.

\section{Enrichment of oxygen}

Similarly, the oxidation fraction across the radial positions in the pellet after 120, 240, and 480 seconds is predicted by enriching the oxygen to have higher partial pressures in the oxidizing gas $(0.21,0.30,0.60$, and $1.00 \mathrm{~atm})$ at $1073 \mathrm{~K}\left(800^{\circ} \mathrm{C}\right)$ using the model, as shown in Figure 7 . The results from the model show that the oxidation proceeds rapidly to near complete oxidation in a rather homogenous manner at higher oxygen partial pressures from 0.21 to $1.00 \mathrm{~atm}$ in the shorter time. 

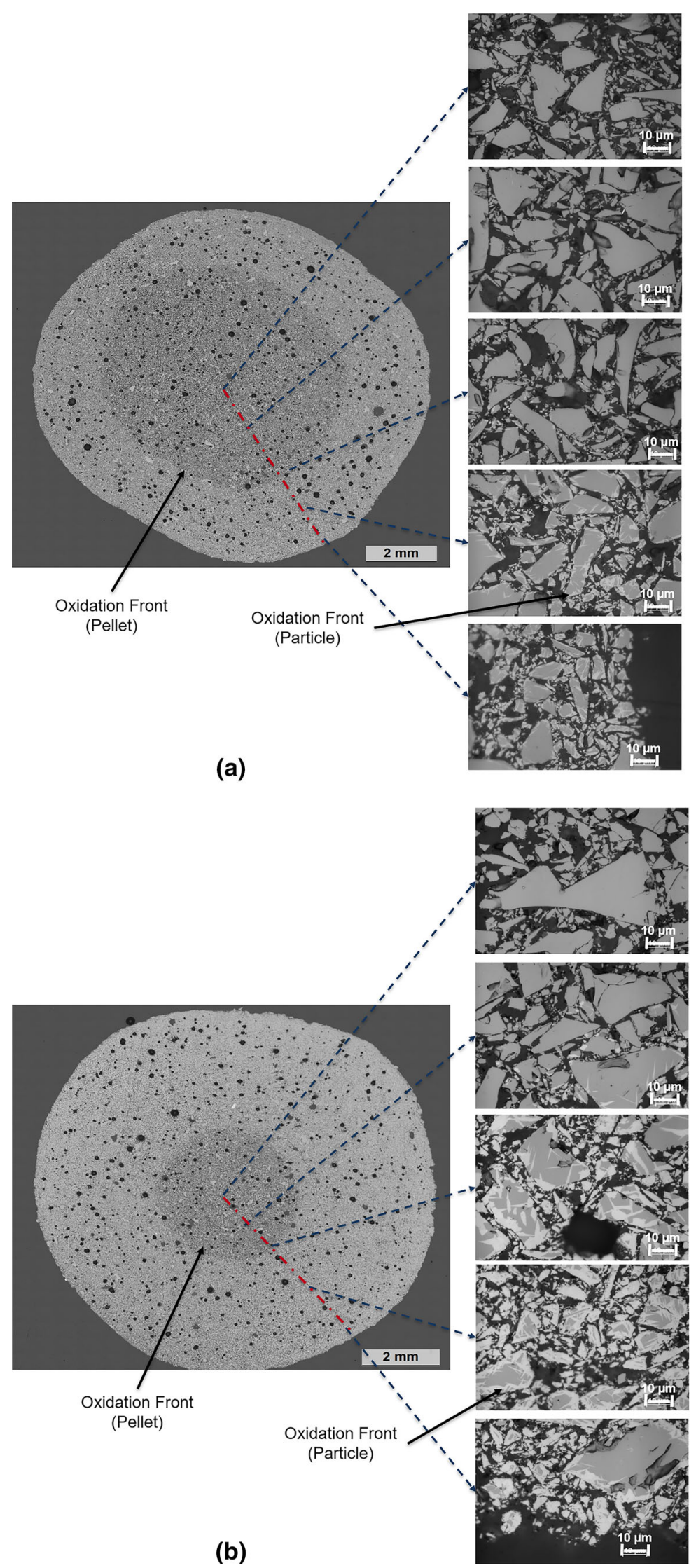

Fig. 4 - Optical microstructure of partially oxidized pellet quenched after $(a) 120 \mathrm{~s}$ and $(b) 480 \mathrm{~s}$ at $973 \mathrm{~K}\left(700{ }^{\circ} \mathrm{C}\right)$ and $p_{\mathrm{O}_{2}}=0.21 \mathrm{~atm}$ at pellet scale and at particle scale across the radial distance at the magnification of $\times 1000$. 


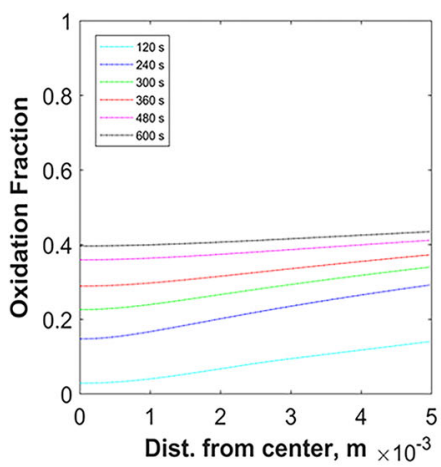

(a)

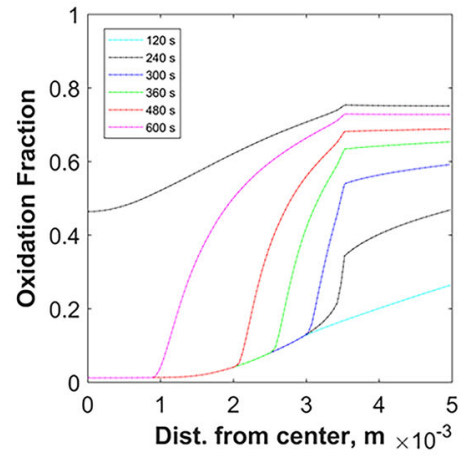

(b)

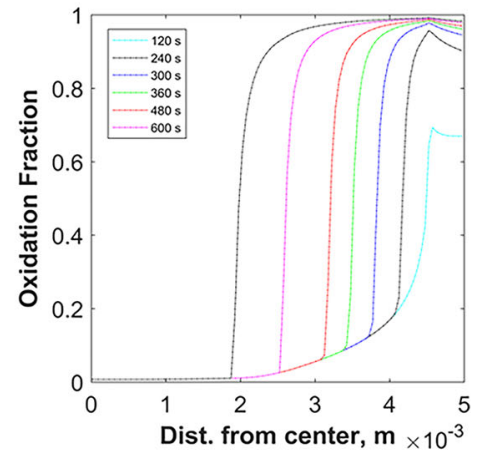

(c)

Fig. 5-Predicted oxidation fraction across radial distance within the magnetite pellets at $(a) 873 \mathrm{~K}\left(600{ }^{\circ} \mathrm{C}\right),(b) 973 \mathrm{~K}\left(700{ }^{\circ} \mathrm{C}\right)$, and $(c) 1073 \mathrm{~K}$ $\left(800{ }^{\circ} \mathrm{C}\right)$ for different time intervals at $p_{\mathrm{O}_{2}}=0.21 \mathrm{~atm}$.
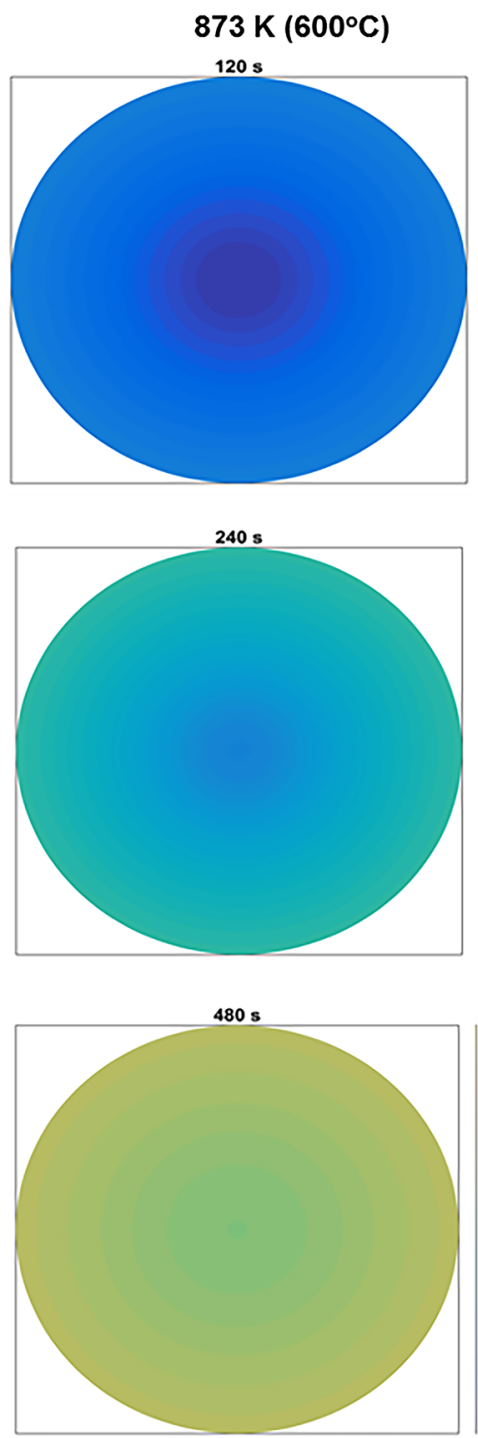

(a)
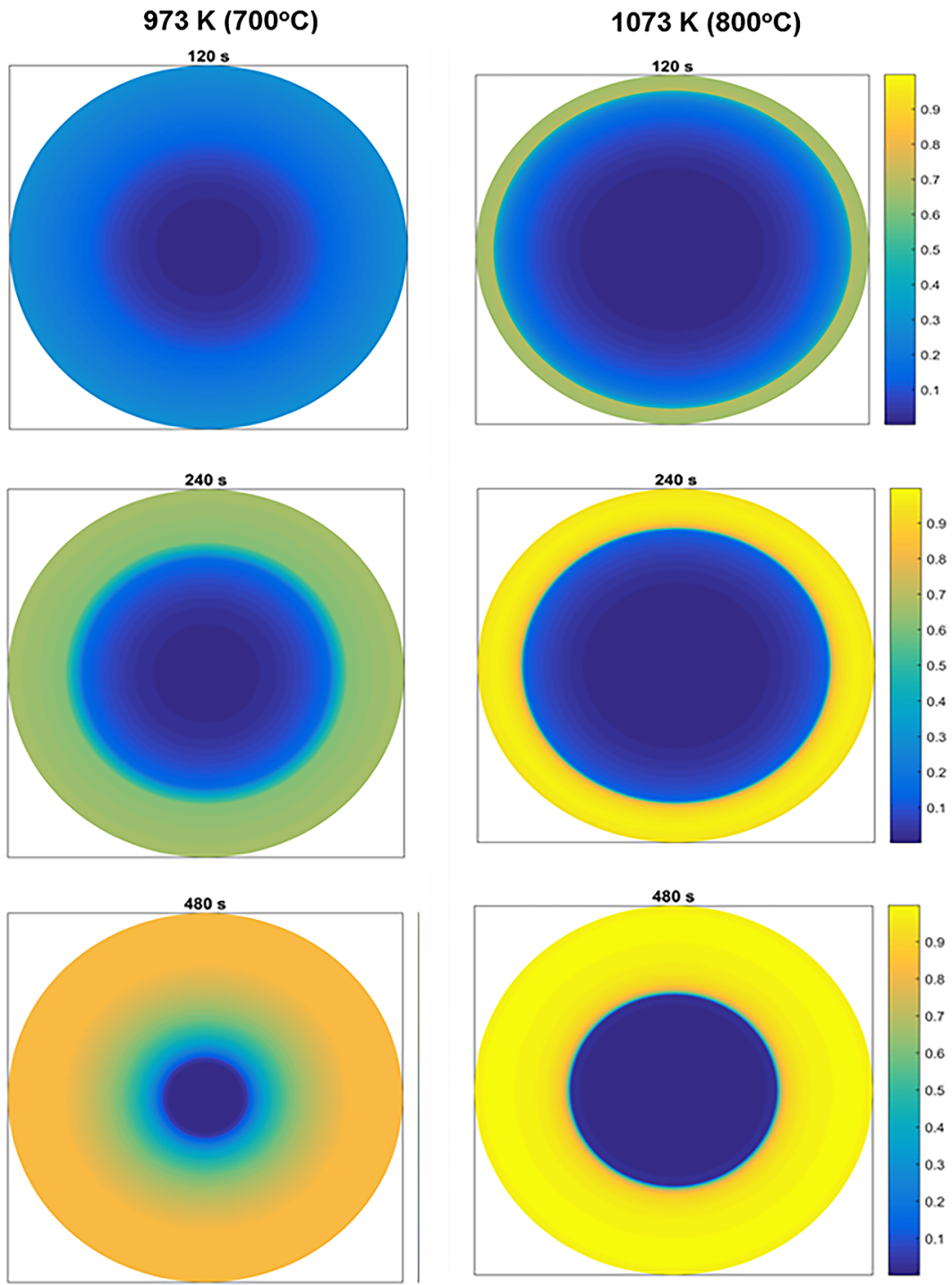

(b)

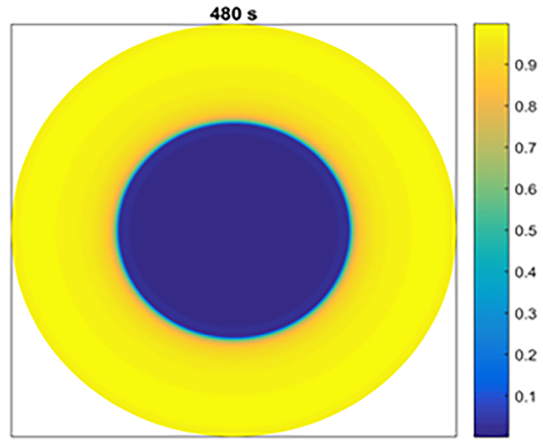

(c)

Fig. 6-Predicted progression of oxidation front within the magnetite pellets at $(a) 873 \mathrm{~K}\left(600{ }^{\circ} \mathrm{C}\right),(b) 973 \mathrm{~K}\left(700{ }^{\circ} \mathrm{C}\right)$, and $(c) 1073 \mathrm{~K}\left(800{ }^{\circ} \mathrm{C}\right)$ after 120,240 , and $480 \mathrm{~s}$ at $p_{\mathrm{O}_{2}}$ of $0.21 \mathrm{~atm}$. 
$21 \% 02$
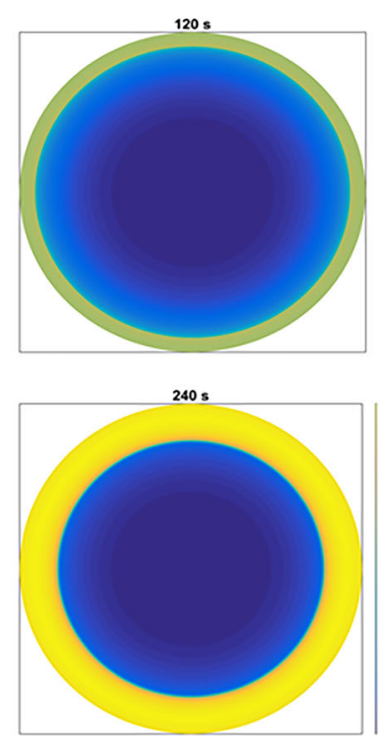

480 s

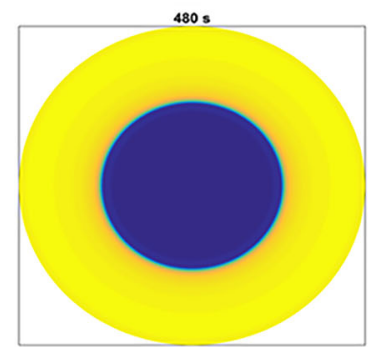

(a)
$30 \% 02$

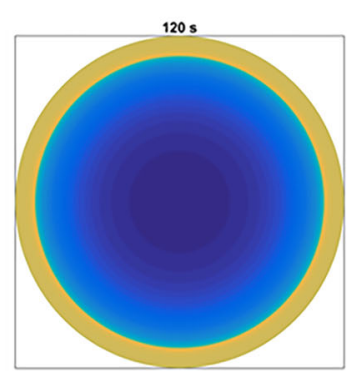

$240 \mathrm{~s}$

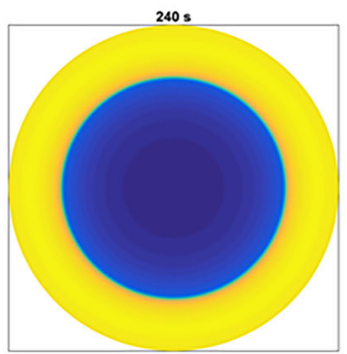

480 s

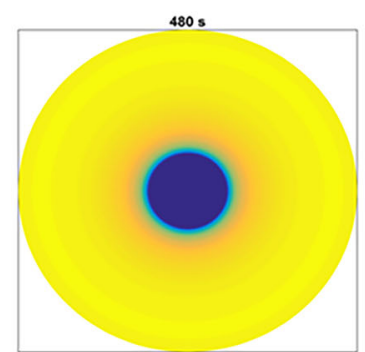

(b)
$60 \% 02$

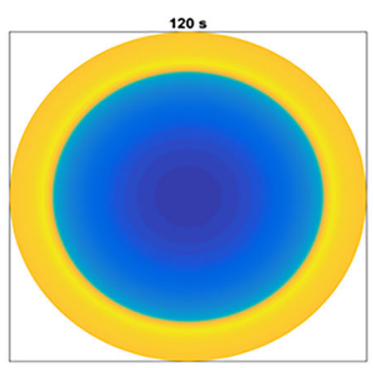

$240 \mathrm{~s}$

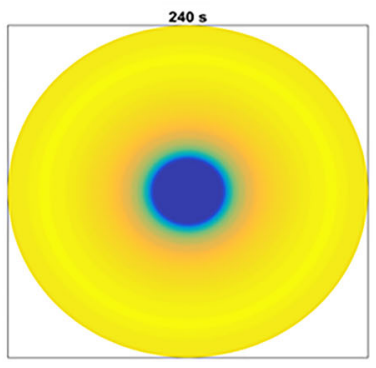

480 s

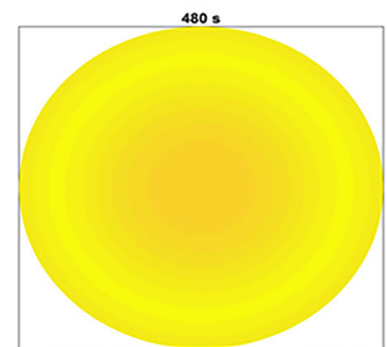

(c)
$100 \% 02$
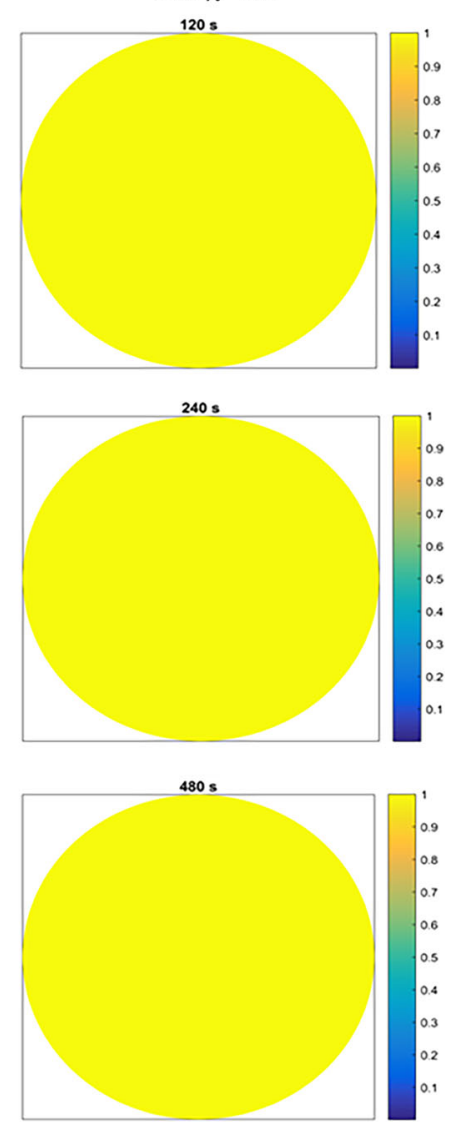

(d)

Fig. 7-Predicted progression of oxidation front within the magnetite pellets at $1073 \mathrm{~K}\left(800{ }^{\circ} \mathrm{C}\right)$ after 120,240 , and $480 \mathrm{~s}$ of oxidation at $p_{\mathrm{O}_{2}}$ of (a) $0.21 \mathrm{~atm},(b) 0.30 \mathrm{~atm},(c) 0.60 \mathrm{~atm}$, and (d) $1 \mathrm{~atm}$.

Thus, it can be considered that the developed oxidation model for magnetite at pellet scale is successfully capturing the entire oxidation phenomenon during induration. This will further help in designing the thermal and gaseous profile necessary to achieve the homogeneously oxidized magnetite pellets before the sintering starts and enable the production of good quality indurated pellets on a consistent basis. According to the model output, it is proposed that the complete and homogeneous oxidation of magnetite pellets can be obtained either by elevating the oxidizing temperature to $973 \mathrm{~K}$ to $1073 \mathrm{~K}\left(700{ }^{\circ} \mathrm{C}\right.$ to $\left.800{ }^{\circ} \mathrm{C}\right)$ or by oxygen enrichment ( 60 pet or 100 pet $\mathrm{O}_{2}$ ) or by the combination of both.

In future, it is planned to incorporate the effect of multi-sized particle distribution at each cell layer into the pellet oxidation model. This will help in refining the model and further improving its efficiency. Additionally, it is also intended to integrate the kinetic oxidation model developed in this study with the sintering models derived earlier ${ }^{[5,6]}$ to develop the overall comprehensive Single Pellet Induration Model (SPIM) for magnetite pellets.

\section{CONCLUSIONS}

The oxidation phenomenon for magnetite at a pellet scale has been investigated experimentally and a mathematical model is developed successfully in this study. The Pellet Oxidation Kinetic Model is built on the approach outlined by the Grain Model for gas-solid reaction kinetics, by incorporating the Avrami Kinetic Model for oxidation kinetics at particle scale. The experiments have been conducted at three isothermal temperatures $\left(873 \mathrm{~K}, 973 \mathrm{~K}\right.$, and $1073 \mathrm{~K}\left(600{ }^{\circ} \mathrm{C}\right.$, $700{ }^{\circ} \mathrm{C}$, and $800{ }^{\circ} \mathrm{C}$ )) and four levels of partial pressure oxygen $(0.15,0.21,0.30$, and $1.00 \mathrm{~atm})$ in the oxidizing gas. The experiments showed that the oxidation rate curves possess two peaks with the peak intensity increasing with temperature, whereas they marginally increase with respect to the partial pressure of oxygen. The same has been complemented well by the results predicted from the pellet oxidation kinetic model. The deviation in the predicted oxidation rate curves from the experiment could be because of the rapid oxidation of fine particles from the distribution of multi-sized parti- 
cles present in pellet, instead of mono-sized particles. These findings have been substantiated by the microstructural investigation at pellet and particle scale.

The model is further used to predict the progress of the oxidation front into the pellet, which is exposed to different temperature and oxygen levels in the oxidizing gas. It is found that when the magnetite pellet is being oxidized at the temperature of $973 \mathrm{~K}$ to $1073 \mathrm{~K}\left(700{ }^{\circ} \mathrm{C}\right.$ to $800{ }^{\circ} \mathrm{C}$ ) at 21 pct $\mathrm{O}_{2}$ or by enriching the oxygen levels $\left(60\right.$ pet or 100 pet $\left.\mathrm{O}_{2}\right)$ at $1073 \mathrm{~K}\left(800{ }^{\circ} \mathrm{C}\right)$ or by the combination of both, one can achieve complete oxidation in the minimum possible time.

\section{ACKNOWLEDGMENT}

Authors thank the Hjalmar Lundbohm Research Centre (HLRC) for their financial support. We also thank Ola Eriksson and Daniel Marjavaara of LKAB for their technical inputs. Thanks are due to Lars-Olof Nordin and Staffan Hedvall of LKAB Metlab, Lulea, Sweden for sample preparation for the microstructural study.

\section{OPEN ACCESS}

This article is distributed under the terms of the Creative Commons Attribution 4.0 International License (http://creativecommons.org/licenses/by/4.0/), which permits unrestricted use, distribution, and reproduction in any medium, provided you give appropriate credit to the original author(s) and the source, provide a link to the Creative Commons license, and indicate if changes were made.

\section{ELECTRONIC SUPPLEMENTARY MATERIAL}

The online version of this article (https://doi.org/10.10 07/s11663-018-1423-4) contains supplementary material, which is available to authorized users.

\section{REFERENCES}

1. K. Mayer: Pelletization of Iron Ores, Springer, Berlin, 1980.

2. S.P.E. Forsmo, S. Forsmo, P. Samskog, and B.M.T. Björkman: Powder Technol., 2008, vol. 183, pp. 247-59.

3. J.R. Wynnyckyj and W.A. McCurdy: Metall. Trans., 1974, vol. 5, pp. 2207-15.

4. B. Yur'ev and N. Spirin: Steel Transl., 2011, vol. 41, pp. 400-03.

5. T.K. Sandeep, N.N. Viswanathan, H.M. Ahmed, C. Andersson, and B. Björkman: Metall. Mater. Trans. B, 2015, vol. 46B, pp. $635-43$.
6. T.K. Sandeep, N.N. Viswanathan, H.M. Ahmed, C. Andersson, and B. Björkman: Metall. Mater. Trans. B, 2016, vol. 47, pp. 30919.

7. T.K. Sandeep, M. Simonsson, N.N. Viswanathan, H. Ahmed, C. Andersson, A.A. El-Geassy, and B. Björkman: Steel Res. Int., 2018, vol. 89, p. 1700366.

8. S. Yagi and D. Kunii: Symp. Combust., 1955, vol. 5 (1), pp. 23144.

9. J. Szekely and J.W. Evans: Chem. Eng. Sci., 1970, vol. 25, pp. 1091-1107.

10. J. Szekely and J.W. Evans: Chem. Eng. Sci., 1971, vol. 26, pp. 1901-13.

11. H.Y. Sohn and J. Szekely: Chem. Eng. Sci., 1972, vol. 27, pp. 76378.

12. D. Papanastassiou and G. Bitsianes: Metall. Trans., 1973, vol. 4, pp. 477-86.

13. D. Papanastassiou and G. Bitsianes: Metall. Trans., 1973, vol. 4, pp. 487-96.

14. J. Szekely: Gas-Solid Reactions, Academic Press, New York, 1974, pp. 143-51.

15. L. Doraiswamy and M. Sharma: Gas Solid and Solid-Solid Reactions, Wiley, New York, 1984, pp. 449-79.

16. J. Edström: Jernkontorets Ann, 1957, vol. 141, pp. 457-78.

17. V. Abzalov, V. Klein, and B. Yur'ev: Steel Transl., 2008, vol. 38, pp. 421-23.

18. T. Hidayat: Metall. Mater. Trans. B, 2009, vol. 40B, pp. 474-89.

19. M. Valipour: Sci. Iran. Trans. C, 2009, vol. 16, p. 108.

20. R. Liang, Y. Shuo, F. Yan, and J. He: J. Iron Steel Res Int, 2013, vol. 20, pp. 16-20.

21. S. Melamud and B. Yurev: Steel Transl., 2016, vol. 46, pp. 384-89.

22. M. Barati: Int. J. Miner. Process., 2008, vol. 89, pp. 30-39.

23. R.A. Davis and D.J. Englund: Can. J. Chem. Eng., 2003, vol. 81, pp. 86-93.

24. K.D. Libsch and S.K. Tarby: Metall. Trans., 1973, vol. 4, pp. 1347-53.

25. J. Thurlby: Metall. Trans. B, 1988, vol. 19B, pp. 103-12.

26. S. Majumder, P.V. Natekar, and V. Runkana: Comput. Chem. Eng., 2009, vol. 33, pp. 1141-52.

27. H. Ahn and S. Choi: Comput. Chem. Eng., 2017, vol. 97, pp. 1326.

28. H.J. Cho, M. Tang, and P.C. Pistorius: Metall. Mater. Trans. B, 2014, vol. 45, pp. 1213-20.

29. H. J. Cho: Ph.D. Thesis 2012, Carnegie Mellon University.

30. J. D. Zetterstrom: Oxidation of Magnetite Concentrates, 1950, Bureau of Mines, USA.

31. H. Schmalzried: React. Solids, 1988, vol. 5, pp. 269-78.

32. J.A. Van Orman and K.L. Crispin: Rev. Mineral. Geochem., 2010, vol. 72, pp. 757-825.

33. H. Mehrer: Diffusion in Solids: Fundamentals, Methods, Materials, Diffusion-Controlled Processes, Springer Science \& Business Media, Berlin, 2007.

34. N.N. Viswanathan, N.B. Ballal, and S. Seetharaman: Diffus. Found., 2015, vol. 4, pp. 139-57.

35. M. Hillert, J. Odqvist, and J. Ägren: Scr. Mater., 2004, vol. 50, pp. $547-50$.

36. T.L. Bergman, F.P. Incropera, D.P. DeWitt, and A.S. Lavine: Fundamentals of Heat and Mass Transfer, Wiley, New York, 2011.

37. T.K. Sandeep Kumar, N.N. Viswanathan, H. Ahmed, A. Dahlin, C. Andersson, and B. Bjorkman: Metall. Mater. Trans. B, 2018 (accepted for publication).

38. N.N. Viswanathan and N.B. Ballal: Treatise Process Metall., 2014, vol. 10 , pp. 658-815.

39. R.B. Bird, W.E. Stewart, and E.N. Lightfoot: Transport Phenomena, Wiley, New York, 1960.

40. M. Avrami: J. Chem. Phys., 1941, vol. 9, pp. 177-84.

41. C. Andersson and B. Björkman: European Coke and Ironmaking Congress, 2011.

42. M. Tang, H.J. Cho, and P.C. Pistorius: Metall. Mater. Trans. B, 2014, vol. 45B, pp. 1304-14. 